\title{
SELF-INCOMPATIBILITY ANTIGENS AND S GENE EXPRESSION IN BRASSICA
}

\author{
M. E. NASRALLAH \\ State University of New College at Cortland, Cortland, N.Y. 13045
}

Received 30.iv.79

\section{SUMMARY}

\begin{abstract}
Immunodiffusion tests performed on stigma extracts belonging to 21 incompatibility genotypes of Brassica oleracea var. acephala and to five genotypes of $B$. oleracea var. capitata showed no cross-reactions among the self-incompatibility (S) antigens found in this tissue. The lack of immunological relatedness between stigma antigens and the inability to detect $S$ antigens in the pollen is exploited in formulating a testable hypothesis for analysing the structure and/or function of the self-incompatibility locus in plants.
\end{abstract}

\section{INTRODUGTION}

IN higher plants, self-incompatibility is attributed to an exchange of molecular and cellular "recognition" signals between the male gametophyte and cells of the pistil (Lewis, 1954; Heslop-Harrison, 1975; Clark and Knox, 1978). Genetic analyses of several species of Cruciferae indicated that multiple alleles at the $\mathrm{S}$ locus control incompatibility (Bateman, 1955; Thompson and Taylor, 1965). The S alleles in the genus Brassica have been shown to produce, in stigma cells, proteinaceous molecules or antigens that are detectable by antibodies obtained following the immunisation of rabbits with stigma homogenates (Nasrallah and Wallace, 1967; Sedgley, 1974; Kučera and Polàk, 1975). Although our earlier immunogenetic studies pointed to a one allele-one antigen relationship in Brassica, it remained to be seen whether cross-reactions between different $\mathbf{S}$ antigens would be encountered. This report indicates an apparent lack of cross-reaction among members of a large sample of $\mathrm{S}$ antigens.

\section{Materials AND Methods}

(i) B. oleracea var. acephala genotypes

Stigmas from the following 21 kale genotypes were collected at the Plant Breeding Institute, Cambridge, England, courtesy of Dr K. F. Thompson (the $S$ allele numbers are those of Thompson). Following harvest, stigmas were allowed to dry overnight at room temperature and stored in airtight vials.

$$
\begin{array}{lllllll}
S_{1} S_{1} & S_{4} S_{4} & S_{7} S_{7} & S_{11} S_{11} & S_{15} S_{15} & S_{18} S_{18} & S_{23} S_{23} \\
S_{2} S_{2} & S_{5} S_{5} & S_{8} S_{8} & S_{13} S_{13} & S_{16} S_{16} & S_{20} S_{20} & S_{25} S_{25} \\
S_{3} S_{3} & S_{6} S_{6} & S_{10} S_{10} & S_{14} S_{14} & S_{17} S_{17} & S_{21} S_{21} & S_{28} S_{26}
\end{array}
$$

Homozygotes for any given allele will be denoted henceforth by the single allele. 
(ii) B. oleracea var. capitata genotypes

Five cabbage genotypes were used with $S$ allele designations assigned independently of the kale material of Thompson. Three genotypes, $S_{1} S_{1}$, $S_{2} S_{2}$, and $S_{3} S_{3}$, were described by Nasrallah and Wallace (1967) and will be referred to as $\mathrm{CS}_{1}, \mathrm{CS}_{2}$, and $\mathrm{CS}_{3}$ in this paper. Two additional genotypes, $\mathrm{CS}_{5}\left(S_{5} S_{5}\right)$ and $\mathrm{CS}_{8}\left(S_{8} S_{8}\right)$, were kindly supplied by Dr D. H. Wallace of Cornell University.

\section{(iii) Antisera against stigma homogenates}

For a description of the two antisera, $\mathrm{AHS}_{1}$ and $\mathrm{AHS}_{2}$, produced against $\mathrm{CS}_{1}$ and $\mathrm{CS}_{2}$ stigma homogenates, see Nasrallah and Wallace (1967) and the protocol given below.

\section{(iv) Antisera against stigma extracts $\left(A E S_{2}\right)$}

Stigma extracts were prepared by soaking dried cabbage $\mathrm{CS}_{2}$ stigmas in buffered physiological saline (phosphate buffer $p \mathrm{H} \mathrm{7.0)}$ for 2 hours at $5^{\circ} \mathrm{C}$ followed by freezing, thawing and collection of supernatant. New Zealand White rabbits were immunised by administering subcutaneously and intramuscularly a $1: 1$ mixture of stigma extracts and Freund's Adjuvant (Difco). During each of the 2nd, 3rd, and 4th weeks, three booster intravenous injections were given per rabbit and the antisera harvested at the end of the 5th week. Extracts from 3000 stigmas were used per rabbit.

\section{(v) Test antigens}

Approximately 15 dried stigmas were pulverised in a spot plate and the resulting powder was suspended in $30 \mu \mathrm{l}$ of buffered saline and then loaded into wells in Ouchterlony double diffusion plates. Testing of kale genotypes was performed at the Scottish Horticultural Research Institute, Invergowrie, Scotland.

\section{(vi) Absorption of antisera}

The absorption procedure with $\mathrm{AHS}_{1}$ and $\mathrm{AHS}_{2}$ was described by Nasrallah and Wallace (1967). With $\mathrm{AES}_{2}$, the absorption was modified by adding 300 dried stigmas of $\mathrm{CS}_{1}, \mathrm{CS}_{2}, \mathrm{CS}_{3}, \mathrm{CS}_{5}$ or $\mathrm{CS}_{8}$ genotypes to $1 \mathrm{ml}$ of antiserum. The resulting mixture was left for 12 hours at $5^{\circ} \mathrm{C}$ and then centrifuged at $2000 \mathrm{~g}$ for $15 \mathrm{~min}$. before using the supernatant in double diffusion tests.

\section{Results}

\section{(i) Stigma tests}

When stigma homogenates from each of the 21 kale genotypes were reacted against heterologously absorbed $\mathrm{AHS}_{2}$ in double diffusion tests, only $S_{21}$ formed a specific precipitation band typical of $\mathrm{CS}_{2}$ (fig. 1). Homogenates of $\mathrm{CS}_{2}$ and kale $S_{21}$ loaded in adjacent wells gave a reaction of identity indicating that the same antigen was present in the two genotypes. Pollination tests had already shown $S_{21}$ of kale to be identical to $\mathrm{CS}_{2}$ (Thompson, 1968). Similar tests with heterologously absorbed $\mathrm{AHS}_{1}$ 
showed that $S_{2}$ of kale produced a precipitation band typical of $\mathrm{CS}_{1}$. Once again, results of pollination tests had shown that the kale $S_{2}$ allele was identical to $\mathrm{CS}_{1}$ (Thompson, 1968). A reaction of identity was evident between $\mathrm{CS}_{1}$ and kale $S_{2}$. However, another kale genotype, namely $S_{7}$, also reacted in a manner similar to kale $S_{2}$ (fig. 2); this fact suggested a possible crossreaction between two different antigens. When Thompson was informed of the results, he kindly checked the tested $S_{7}$ genotype by appropriate pollinations and concluded: "The clones, from which stigmas were obtained for allele $S_{7}$, were heterozygous for alleles $S_{7}$ and $S_{2}$, confirming the serology results" (Thompson, personal communication). The precipitation band opposite $S_{7}$ (fig. 2) is in all probability due to the presence of the $S_{2}$ antigen in the tested line, and does not therefore represent a cross-reaction.

A second antiserum against $\mathrm{CS}_{2}$ stigma extracts $\left(\mathrm{AES}_{2}\right)$ gave results consistent with those of $\mathrm{AHS}_{2}$. Absorption of $\mathrm{AES}_{2}$ with each of $\mathrm{CS}_{1}, \mathrm{CS}_{3}$, $\mathrm{CS}_{5}$, and $\mathrm{CS}_{y}$ stigma homogenates gave a precipitation band opposite the $\mathrm{CS}_{2}$ genotypes in double diffusion tests. Absorption of $\mathrm{AES}_{2}$ with homozygous or heterozygous genotypes carrying the $\mathrm{CS}_{2}$ allele abolishes all precipitation bands indicating complete absorption of the antiserum.

\section{(ii) Pollen tests}

Pollen, mature anthers and young developing anthers including both pre-meiotic and post-meiotic stages were homogenised in buffered saline and reacted at different concentrations against $\mathrm{AHS}_{1}, \mathrm{AHS}_{2}$, and $\mathrm{AES}_{2}$. Immunodiffusion tests similar to those used with stigma homogenates failed to reveal detectable levels of $\mathrm{CS}_{1}$ and $\mathrm{CS}_{2}$ stigma antigens in $\mathrm{CS}_{1}$ and $\mathrm{CS}_{2}$ pollen or anther tissue. Furthermore, whole pollen, pollen homogenates and anther homogenates were used as absorbing antigens with $\mathrm{AHS}_{1}, \mathrm{AHS}_{2}$ and $\mathrm{AES}_{2}$. The absorbed antisera formed the characteristic $\mathrm{CS}_{1}$ and $\mathrm{CS}_{4}$ precipitation bands with the respective stigma homogenates, with no detectable weakening, and therefore no apparent absorption of the $S$ specific antibody molecules.

\section{Discussion}

The self-incompatibility system is useful for exploring the control of the highly specific recognition mechanism between cells of pollen and pistil. The pollen component of the $S$ allele system has yielded least to inquiry and little is known about its control (Heslop-Harrison et al., 1974; Ferrari and Wallace, 1976). On the other hand, the stigma reaction was shown to be mediated by proteinaceous molecules that are readily detectable by immunochemical methods (Nasrallah and Wallace, 1967; Nasrallah, Barber and Wallace, 1970). Such findings had led us to postulate that, in the stigma, the $S$ alleles function by each producing a unique polypeptide, the primary structure of which determines its antigenic properties. However, in the light of the data presented here, it is difficult to reconcile this hypothesis with the demonstrated absence of cross-reactions among the large number of $S$ antigens examined to date. Had the $S$ antigens been polypeptide variants of one protein species, one would expect that immunological cross-reactions between such biochemically related molecules would have been uncovered.

In view of the above and of the recently reported correlation of $S$ alleles 
with specific PAS-positive molecules (Hinata and Nishio, 1978), and alternative mechanism of gene action is presented. It envisages the function of alleles at the $S$ locus as that of linking specificity markers such as sugars or sugar derivatives to a proteinaceous core molecule coded for by another locus (or loci). Evidence for the involvement of more than one locus in incompatibility systems has been demonstrated in several angiosperm families (Lundqvist, 1975) and in a self-fertile mutant of Brassica (Nasrallah, 1974). The $S$ controlled markers could conceivably take part in the interactions that lead to incompatibility and also act as haptens that help elicit the observed antibody response. Ultimately, the characterisation of the structure of the stigma antigens will settle this question.

As for the pollen determinants of specificity, our results indicate that in Brassica, the S stigma antigens are not found in this tissue as is the case in Oenothera (Lewis et al., 1966) and Petunia (Linskens, 1960). It appears that in Cruciferae, the pollen recognition molecules are not identical to those of the stigma, and therefore that different genetic units are responsible for the pollen reaction. Regardless of the precise structural organisation of the $S$ gene complex, the function of the pollen genetic elements must be closely co-ordinated with their stigma counterparts. As a working hypothesis, it is postulated that such co-ordination is achieved by the expression of a specific glycoprotein antigen in the stigma, and of a complementary but different receptor molecule in the pollen.

Acknowledgment.-The author is indebted to Dr K. F. Thompson of the Plant Breeding Institute, Cambridge, U.K., for the kale material and for testing the $\mathrm{S}_{7}$ genotype and thanks Drs. Chris North and Tony Wills and other members of the Plant Breeding and Virology groups at the Scottish Horticultural Research Institute, Invergowrie, Scotland, for their hospitality and extensive assistance in almost all aspects of the work.

\section{REFERENCES}

Bateman, A. J. 1955. Self-incompatibility systems in angiosperms. III. Cruciferae. Heredity, 9, 53-68.

ClARKE, A. E., AND KNOX, R. B. 1978. Cell recognition in flowering plants. Quant. Rev. of Biol., 53, 3-28.

FERrari, T., AND WAllace, D. H. 1976. Pollen protein synthesis and control of incompatibility in Brassica. Theoret. Appl. Genetics, 48, 243-251.

HESLOP-HARRISON, J. 1975. Incompatibility and the pollen stigma interaction. Ann. Rev. Plant Physiol., 26, 403-524.

HESLOP-HARRISON, J., KNOX, R. B., AND HESLOP-HARRISON, Y. 1974. Pollen wall proteins: exine-held fractions associated with the incompatibility response in Cruciferae. Theoret. Appl. Genetics, 44, 133-137.

hinAtA, K., AND Nishio, T. 1978. S-allele specificity of stigma proteins in Brassica oleracea and $B$. campestris. Heredity, 41, 93-100.

KUČERA, V., AND POLÀk, J. 1975. The serological specificity of $\mathrm{S}$ alleles of homozygous incompatible lines of the narrow-stem kale (Brassica oleracea var. acephala DC) Biol. Plant., $17(1)$, 50-54.

LEWIS, D., 1954. Comparative incompatibility in angiosperms and fungi. Adv. Genet., 6, 235-285.

LEWIS, D., BURRAGE, S., AND WALLS, D. 1966. Immunological reactions of single pollen grains, electrophoresis and enzymology of pollen protein exudates. J. Exp. Bot., 18, $371-378$.

Linskens, H. F. 1960. Zur Frage der Enstehung der Abwehr-Korper bei der Inkompatibilitäts reaktion von Petunia III. Z. Bot., 48, 126-135.

LUNDQVIST, A. 1975. Complex self-incompatibility systems in angiosperms. Proc. Roy. Soc. Lond., B 188, 233-245. 
NASRAllah, M. E. 1974. Genetic control of quantitative variation in self-incompatibility proteins detected by immunodiffusion. Genetics, 76, 45-50.

NASRALlaH, M. E., BARBER, J. T., AND WALlace, D. H. 1970. Self-incompatibility proteins in plants: detection, genetics and possible mode of action. Heredity, 25, 23-27.

NASRALLAH, M. E., AND WALLACE, D. H. Immunogenetics of self-incompatibility in Brassica oleracea L. Heredity, 22, 519-527.

SEDGLEy, M. 1974. Assessment of serological techniques for S-allele identification in Brassica oleracea. Euphytica, 23, 543-55I.

THOMPSON, K. F., AND TAYLOR, J. P. 1965. Identical $\mathrm{S}$ alleles in different botanical varieties of Brassica oleracea. Nature, 208, 306-307.

тномpson, к. F. 1968. Classified S alleles for Brassica breeders. Proc. Eucarpia meeting on Brassica, 1968. Horticultural section: 4-6 September, Wellesbourne, England. Ed. G. E. Dixon, 25-28. 